Wilson S, Belonging in difficult family circumstances: Emotions, intimacies and consumption. In: Casey E, Taylor Y (ed.). Intimacies, critical consumption and diverse economies, 2015, Palgrave Macmillan reproduced with permission of Palgrave Macmillan.

This extract is taken from the author's original manuscript and has not been edited. The definitive, published, version of record is available here: http://www.palgrave.com/page/detail/Intimacies-Critical-Consumption-and-Diverse-Economies/? $\underline{\text { sfl }=\text { barcode \&st } 1=9781137429070}$

\title{
6
}

\section{Belonging in Difficult Family Circumstances: Emotions, Intimacies and Consumption}

\section{Sarah Wilson}

Much work on young people's material and consumer cultures has focused on the relatively affluent, and on those living with their parents. This chapter is concerned with the often more problematic material and affective circumstances of young people whose family difficulties have led them to be 'looked after' by the state. In particular, it focuses on the significance of material objects in helping to construct (or not) a sense of belonging, however ambivalent, in often successive places of residence. Further, while there has been much policy and research discussion of young people's use of consumer items affording access to the internet and other electronic means of communication (Livingstone and Haddon, 2008; Livingstone et al., 2012; Osvaldsson, 2011), this chapter focuses on the importance of items of lesser monetary but often great affective or 'sentimental' value. As such, it draws on and develops recent literature on the role of consumption and material culture (Miller, 2008; 2010) in producing the self as a person who 'belongs' (May, 2013), and who can 'display’ a family (Finch, 2007).

In addition, this chapter discusses the research interview itself, in particular where, as in the project discussed, visual (and audial) methods are employed, as a place in which families and relationships may be 'displayed', through photographs of material objects and places or drawings of 'ideal homes'. The chapter also explores the consumption of the artefacts produced in such research. On the one hand, these artefacts are analysed as possible means of drawing sympathetic attention to the material and relational absences and fragility associated with difficult family circumstances. It is argued that these items, if carefully used, have the potential to evoke the type of 'haunting' in a wider audience discussed by Gordon (2008) as a potential prompt for changes in the public imagination of groups whose difficult circumstances tend currently to be understood in individual terms. At the same time, the potentially more negative effects of research council requirements to evidence research 'impact' and to archive all data produced are addressed. In particular, the potential for archived photographic data to fix and reinforce stigmatised representations of difficult circumstances, and by extension of those associated with them, is discussed.

The next section will introduce the study on which this chapter is based, and the sensory methods (Pink, 2009; Rose, 2007) it employed, before discussing participants' material cultures in terms of ideas of 'haptic belonging' (May, 2013), practices of family ‘display’ (Finch, 2007) and 'haunting' (Gordon, 2008). 


\section{Methodological background}

The ESRC-funded project on which this chapter primarily draws was a qualitative study of the sensory and spatial construction of (not) belonging, whether positive, negative or ambivalent, with currently or formerly 'looked after' children in Scotland. From 2011-2012, the researchers worked with 22 young people (13 men, 9 women aged 10-23 but primarily 10-18) from urban, rural and island communities across Scotland, recruited through voluntary sector organisations or statutory social work services. As such, the sample reflected consumption in different geographical contexts, including less researched remote islands. In addition, the sample reflected a variety of official living arrangements. Four participants were living independently having left care, but all had experienced a range of different, and often successive, official placements, including foster, kinship, secure and residential care. All the young people participated in the first interview and 14 completed a second interview. In these interviews, photos, sound recordings, and drawings produced by the respondents were discussed. Subsequently, six young people also participated in producing films and music to disseminate project themes. ${ }^{1}$

The interviews and the visual and audial methods employed in this project built upon the researchers' previous work (including Milne et al., 2012; Wilson et al., 2012a, b; Wilson, 2014) and guidance from a project advisory group that included a young woman with experience of multiple, diverse living arrangements in adolescence and subsequently of being a kinship carer. ${ }^{2}$ Ethical advice and approval was received from a University ethics committee, and from several of the organisations through which respondents were recruited. The first interviews were preceded by an introductory meeting in which potential participants were talked through the researchers' broad directions for taking photos and recording sounds (what Rose (2007) calls the interview 'running script'), as well as the ethical implications of taking pictures that might identify or incriminate themselves or others. In these interactive sessions, potential participants were also given the chance to play with the equipment, to ask questions, and to consent (or not) to differing potential uses of the data produced.

In preparation for the first interviews, participants were asked to record sounds (and one musical track) that were important to them and to take photographs of their favourite and least favourite spaces (where they felt most and least 'at home'). Reflecting the literature on different types of physical and less tangible spaces, the script did not limit the participants to where they lived, nor to conventional domestic spaces. Such 'photo-elicitation' - as well as drawing exercises - has often been used with children and young people in research into the meanings they give to particular places (Morrow, 2001; Rasmussen, 2004). However, unlike in this project, such exercises have often reproduced conventional distinctions between the 'home' and public spaces with explorations of the former limited to domestic spaces (Wilson, 2014). If participants did not want to, or could not, take a photograph of a particular place, they were asked to download an Internet image to represent it, or this was done during the interview itself. Particularly 
relevant to this chapter on consumption, they were also asked to take photographs of three highly personally significant objects or 'things'. The resulting visual and audial data or artefacts formed the basis for the first interview discussion. In the second interviews, participants' first interview data and responses were revisited. They were also invited to discuss music tracks, which contained messages they wanted others to hear, and to complete drawings of their ideal and current living places. The use of these methods was 'multi-sensorial' in the sense that it was not expected that the data produced from more visual methods would primarily reflect visual experience, or, indeed, that sensory experience can be so divided. As Rose (2007, pp. 238-239) argues, photos 'carry flesh and blood', encouraging talk that would not have been possible in their absence. Audial methods have been employed much less frequently. (Allett, 2010). The author drew on DeNora's (2000) and Bull's (2007) research into the uses of music in everyday life, and her sense of the importance of music and sound in general to lived experience, to develop the innovative audial methods employed in this project.

The respondents' photographs, sounds, drawings and music tracks were discussed in very loosely-structured, largely participant-led and often long (1-4 hours) interviews. Pink (2009, p. 9) advocates the use of participatory 'practices' that 'seek to understand and engage with other people's worlds through sharing activities, practices and inviting new forms of expression'. While we did not 'do' the activities identified alongside the participants in quite the manner Pink advocates, the process of downloading and looking at the data they produced seemed to lend a sense of non-threatening proximity and collective, creative endeavour to the interviews, providing insights into their attempts to create a feeling of belonging across a broad range of spaces. In addition to producing rich data, the use of such participatory methods, in which direct questioning employing emotive terms such as 'belonging' itself was avoided, seemed less intrusive than some of the author's previous experiences of conventional face-to-face interviewing (Wilson, 2014). At the same time however, later discussions with one older participant and the subsequent process of writing about the project suggested the potential for some of the images taken, and discussions of these, to 'stay with' or haunt (Gordon, 2008) the involved parties long beyond the project's practical 'end' in both positive and potentially more negative ways. This experience lead to further reflections related to the 'impact' of research projects.

This chapter will draw particularly on discussions of the photographs respondents took of favourite objects as well as material relating to photographs of spaces and drawings of 'ideal homes'. In the following sections, the project findings in relation to the artefacts produced will be discussed in relation to ideas of 'haptic' (or sensory) belonging (May, 2013), 'display’ (Finch, 2007) and 'haunting' (Gordon, 2008) respectively. 


\section{Haptic belonging, display and haunting}

\section{Creating a sense of haptic or sensory belonging}

The respondents photographed and discussed a wide variety of objects. These included many electronic items including computers and mobile phones, the significance of which in terms of communication, engaging with music and as techniques of self-care is discussed elsewhere (Wilson, 2015 forthcoming). In some instances, articles associated with substance or alcohol use were highlighted. Many objects had no such practical significance in everyday life, however, and often little monetary value. These items included teddies and other soft toys, even among older respondents, as well as photos (of birth family members, former foster carers, siblings), a guitar, a family tartan, a set of samurai swords, wallpaper and several (sometimes broken) clocks. The significance of some of these items was further underlined over the course of the project as the circumstances of the participants changed.

The importance of 'transitional objects' has long been recognised in social work practices such as creating 'memory boxes' for the deposit of significant objects and 'life story work' to create records of little-remembered periods (Brodzinsky et al., 1998; Baynes, 2008). The importance of such work is often explained in terms of the difficulty that bereaved children, or those removed from their family, may have to remember or find out about significant people and important events, as well as their need to work through difficult past circumstances. The latter is also associated in psychological terms with developing 'emotional literacy' or the ability to express and discuss emotions.

In the context of this project, sociological work on belonging, relationships and material culture also proved helpful in thinking through the data. According to May, '[b]elonging can be characterised as feeling at ease with one's self and one's social, cultural, relational and material contexts' (2013, p. 14). Many of the items or keepsakes discussed seemed to be associated with a sense of 'haptic' (or sensory) belonging (May, 2013) or 'home' through their visibility, texture and smells. Drawing on Miller (2008), May argues for example that '[o]bjects can store and possess emotions, and can, for example, represent deceased people and allow the bereaved to continue a relationship with them even after death' (2013, p. 144). In this project, teddies and other soft toys provided something physical to hug and even to talk to. Furthermore, some respondents claimed that these toys also carried the familiar smells of important people including relatives, former social workers and others. Often it seemed unlikely that such an item could have retained a smell over so many years, but the 'reality' seemed less important than their imagination of this continued, tangible presence.

Similarly, in her first interview, Channel $^{3}$ (18, foster care) presented several photos of her aunt's living room, commenting at length on the 'feel' of the décor and colour scheme there, particularly the wallpaper. She spoke about the calming effects of this wallpaper during the day when she liked to spend time there alone, and at night when 
the silvery flowers on the darker background shone and the room was filled with people, many of whom were her relatives:

SW: Is that one of your favourite places...(A-ha). It is? What do you like about it?

$\mathrm{CH}: \quad$ The room...the colours, the theme ...

SW: The theme and the colours.

CH: I just like it. It's my favourite colours.

SW: Kind of brown?

CH: It's like silver and blue.

SW: A-ha. And is it soothing?

$\mathrm{CH}: \quad$ It's calm and relaxing ...

SW: OK. So when you go round there, is it usually full of your friends?

CH: No, just at night. But I'm in it myself during the day. To calm down. ... Aye, can you see the colours now? ... (Yes) that's the colours that get lights that I like.

Through our discussion it emerged that she associated this place and the colour scheme -which she had also tried to reproduce in her re-decoration of the friend's flat where she spent most of her time- with her recently deceased and much-loved grandfather. This connection, and the fact that this was one of the few places to which she had had continual access, and which had not changed over a long period during which she had been moved between various foster placements, was very important to her. Channel explained the significance of the room in this photo in very sensory terms therefore that seemed to reflect May's idea of haptic belonging. At the same time, the photo itself may be interpreted as a means of 'displaying' family connections to the interviewer (and beyond). This idea of 'display' will be explored in the following section.

\section{'Displaying' family at home, on the move and in the interview}

Finch's work on the importance of everyday and routine 'display' as 'an activity which characterizes contemporary families' (2007, pp. 65-66) was also useful in interpreting the items photographed and ideal places drawn and discussed by the participants. Finch's emphasis on the importance of 'display' in empirical and conceptual terms draws on Morgan's work on 'family practices' (1996). The latter shifted understandings of 'family' away from particular structures to focus on the way family and other relationships are 'done' in everyday activity or routines; ' $[\mathrm{t}]$ he focus is on the quality of relationships, and how they are expressed in practical actions therefore' (Finch, 2007, p. 70). Drawing on these arguments, Finch (2007, p. 66 emphasis in the original) contends that 'families need to be "displayed" as well as "done"' and further (2007, p. 66) that 'the meaning of one's actions has to be both conveyed to and understood by relevant others if those actions are to be understood as constituting "family practices"'. She 
provides several examples of 'display' including non-resident fathers' activities with their children post-parental separation, relationship narratives and 'keepsakes' such as 'photographs or domestic artefacts' (2007, p. 77). In the context of this study, photographs of keepsakes and the participants' narratives about them proved particularly important.

Finch (2007, p. 77) also refers to particular circumstances, where 'relationships move further away from those which are readily recognisable as constituting family relationships', in which display may be particularly important. In particular, she mentions same-sex and other 'chosen' families, separated households post-divorce and transnational family relationships in which 'family' and 'household' do not (easily) coincide. Crucially, she also argues that 'the process of seeking legitimacy entails displaying one's chosen family relationships to relevant others and having them accepted' (2007, p. 71) and that '[b]eing recognized as having 'a family' just like anyone else is an essential part of this agenda' (2007, p. 74: emphasis in original). For Illouz (2007), being able to make such a claim and to have it recognised by others, is crucial to the prevalent 'psychoanalytic imagination' of the construction of self and identity. In this way, she argues that in contemporary 'Western' society there has been an increasing ideological emphasis on the centrality of the nuclear family to healthy child development, and that those who cannot lay claim to such a family, may be seen as 'damaged'. For 'looked after' young people who cannot live with their families of origin and/or have very fragile or non-existent relationships with parents who could not care for them as expected, the importance of being able to 'display' some kind of family might be seen as particularly heightened.

However, 'displaying' family is often more difficult for young people than for co-resident adults who tend to have greater control over what is displayed on the semi- public walls of living rooms. Photographs of important people were displayed by participants where they could, and were discussed in their interviews. This display took various forms. Part of the significance of mobile phones, for example, was that photos could be taken and stored on them, transported between different locations and shown to different people there. Several participants also discussed photographs of loved ones that they kept in their bedrooms. Jodie (15, residential care) discussed the photo of her former foster parents and their dog displayed in her room. Through her prominent presentation of this photo in a conventional frame, and through her identification of it as one of her most important items and discussion of it in the interview, Jodie may be seen as asserting her claim to a more conventional family set-up than the one in which she now lived. For example, in her interview she also emphasised that she would be spending her imminent birthday with these foster parents:

EJ: That's good, that's good. So why have you taken this photo for me?

JODIE: It was just to show you who they [foster parents] were and that was kinda like a good memory, like a memory of them. 
JODIE: Cause I've not got a picture of them on my computer so I thought I'd take a picture of that so I can put it on my computer.

EJ: And is this a photograph?

JODIE: Yeah it's a photograph, it's a photograph in a frame.

EJ: Where does it... where d'you keep it?

JODIE: In my room...

EJ: ... Who gave this to you?

JODIE: [Foster parents], they gave me it.

EJ:

How did you feel when they gave it to you?

JODIE: Happy!

EJ: Yeah, so it was nice that you had a photo of them?

JODIE: Yeah.

EJ: That's really nice. So they'll be coming for your birthday, doing a big celebration?

JODIE: Yeah, we're going to have a party in the house and after that we're going to go to the cinema.

Several other participants also presented pictures of former foster parents in this way, thus asserting the familial nature of these connections.

An interview with Penfold (14, foster care) suggested that items might be displayed for other reasons too. He took a photograph of a guitar hanging on his bedroom wall. His explanation of its significance seemed to relate to maintaining a sense of consistent self from before he could remember and in spite of multiple moves, and of having a talent somewhat separate from his new foster family and from all the many others with whom he had lived. The guitar seemed therefore to provide a means of displaying a comfortable sense of non- or ambivalent belonging:

SW: $\quad$ So why did you take a picture of this guitar? Is it specifically this guitar or guitars in general?

PENFOLD It's just special. I've had that since I was so young and... even if it breaks I'll still keep it, it's just an amazing guitar.

SW: Why is it so amazing?

PENFOLD: $\quad$ Just cause it's a good memory when I was younger and I remember when I used to play it. SW: $\quad$ Did you used to play it on your own or did somebody teach you to play?

PENFOLD: On my own. 
SW:

Wow! So did you teach yourself to play guitar?

PENFOLD: $\quad$ Mm hmm, since I was the age of four I taught myself.

SW: $\quad$ And how did you get hold of this guitar?

PENFOLD: I don't know.

SW: It's just always been there?

PENFOLD: Aye.

SW: [Laughter] and everywhere you've lived you've taken this guitar with you?

PENFOLD: $\quad$ Mm hmm.

SW: $\quad$ D'you play it much anymore?

PENFOLD: $\quad$ Mm hmm, I still play it all the time.

Not all such keepsakes referred back to the past or previous living arrangements. Tiger (10, foster care) had few things from before his current placement but had taken up his 'adoptive' brother's hobby of collecting animal ornaments:

TIGER: I just like lions, I like big cats as well, but I really like all animals really.

EJ: $\quad$ So how long have you been collecting these for?

TIGER: Started 2010 or something.

EJ: $\quad$ Is that when you moved here?

TIGER: No, moved here in about 2008.

EJ: $\quad$ Okay, so you took a while to see what [your adopted brother] was collecting and just see what was what and then you started doing it, and d'you think you're gonna carry on collecting?

TIGER: Yeah.

Tiger presented photos of these items as some of his most important objects in his interview. In this way perhaps, as Finch speculates in relation to 'chosen' families, he seemed to assert his current, non-biological adoptive family as his 'real' and future family, as well as his desire to disassociate himself from a difficult past and to emphasise how happy he was in his current circumstances. Dylan (18, living independently) had fewer such resources with which to assert a past or current family since he had little contact with either his birth family or his former foster mother. However, he did take a picture of an item associated with the latter. He also spoke at some length about nametags, inspired by the television series ' 24 ', which he had sent for online emphasising that several of his friends had also ordered them. It is argued that his emphasis on these nametags may be seen as another attempt to display connection into the future, however fragile.

In addition to merely representing the keepsakes the young people displayed primarily in bedrooms, the interviews themselves seemed to provide a further opportunity to display family relationships and to have these 
recognised or at least recorded. Certain photos, drawings and discussions illustrated this observation particularly well.

Mackenzie (14, foster care), for example, insisted on taking a photograph of boxes of birthday presents she was going to send to a brother she saw several times a year. It seemed that she wanted this ephemeral event that illustrated her relationship with him to be recorded in some way. Where the participants were in secure care, everyday display, and indeed taking photos for the project, was more difficult, if not impossible. However, the interviews provided these participants with other activities through which to imagine the possibility of such display and to bring them into existence through discussion and sometimes drawing. For example, Thomas (14, secure unit) could not display pictures of the inherited swords and clan shield that he spoke of as so important to him, but he could discuss them in his interview and identify a space for them imaginatively in his second interview drawings of his ideal home. It may be therefore that in such instances where the resources to affirm family were particularly limited, the interview process provided a rare and valuable opportunity to display family connection.

\section{Haunting including in the research process}

Such findings illustrate then the profound importance of particular items or keepsakes to the participants in terms of both 'haptic' belonging (May, 2013) and the possibility these items provided to 'display' (Finch, 2007) family connections and have them accepted by others. It also seemed that the research process of taking pictures for, and their discussion in, the interview provided important possibilities for display in difficult circumstances. At the same time, the interview discussions pointed to circumstances where holding onto such items and their display might be very difficult, if not impossible. Further, the emotional significance of some of the items portrayed in photos or discussed in interviews could also be double-edged conveying loss and sometimes feelings of emptiness in particular places of residence, as well as connection to past relationships and to good memories, as discussed in the two sections above. In the following section, the capacity of such visual artefacts, produced through research, to draw the attention of viewers- researchers and potentially a broader public- to the lived experience of structural disadvantage is explored. At the same time, the potentially negative effects of this capacity of photos and drawings to 'stay with' participants and viewers beyond the interviews will also be discussed.

In her important book 'Ghostly Matters', Avery Gordon (2008, p. 4) urges sociologists to pay greater attention to the 'complexity' of ordinary experience and to the importance of 'haunting' or (2008, p. 196) 'see[ing] the things and the people who are primarily unseen and banished to the periphery of our social graciousness'. She further argues that it is important that sociologists, through their methods, register some of the aspects and effects of power and disadvantage that do not fit easily into 'neat' sociological categories. Employing characteristically poetic language, she (2008, p. 3) points to the way that power: 'can drown you in the present ..., cause bodily injury, ... harm you without ever seeming to touch you [and] arrives in forms that can range from ... state terror to "furniture without 
memories"'. In her view, 'ghosts', which can represent both loss but also the possibility of different future possibilities, may connect a researcher with such understandings. Drawing on Raymond Williams' (1977) idea of a 'structure of feeling', she also emphasises that a ghost 'articulates presence' (1977, p. 135) as the tangled exchange of noisy silences and seething absences. Such a tangle - as object and experience- is haunting' (2008, p. 200).

Several of the items photographed and discussed by participants, such as Thomas and Mackenzie for example, might be seen in this way, reflecting the 'seething absence' of the possibility of living with parents or siblings, as well as their attachment to family memories and relationships. Similarly, Dylan's photo of his cat wearing a bell to provide him with company, simultaneously pointed to his love of this cat, but also to his frustration and loneliness. Further, Reggie's (23, living independently) photos of objects tended to emphasise a very individual, solitary identity, rather than connection to, or display of, family or community. For example, in his discussion of a photo of his varnished nails he emphasised how he could not wear nail varnish (an 'important object') in the area in which he lived for fear of being 'gubbed' [beaten up] and how other members of his family had questioned his sexuality when he painted his nails within the home.

Similarly, Reggie included a photograph of a bag to emphasise that he was always on the move between different places, and specifically emphasised that he had few possessions since 'having too much just slows you down'. He also produced several images of his tattoos; uniquely portable mementoes of periods in his life etched on his skin. In his view, these tattoos, even those he no longer liked, were permanent visual representations of his life story. However, his love of tattoos, and the designs he drew for tattoos he could not afford, also seemed to reflect his searching, even a yearning, for an adult, masculine identity, drawing, for example, on Maori culture:

REGGIE: [Laughs] oh that erm started out as a tattoo idea, erm, it was meant to be tribal, erm, tattoos are quite a big thing for me...

SW: $\quad$ Yeah, why d'you like tattoos so much?

REGGIE: I dunno, like, when I was younger it started out as 'that's my way to show I'm a man!' [laughs]

SW: Uh huh, so it's to do with masculinity?

REGGIE: I don't think so anymore, but when it started it was, yeah...

SW: Yeah.

REGGIE: ... it was very much oh well that's your rite of passage so you get a tattoo, okay, and now I don't like my first one, so erm... it's kind of, I don't know ... Like the Maoris and all that, they do their tattoos but that's very much a rite of passage, you need to get it or you are not a man, that type of thing. 
It seemed that in his reading of them, such traditional cultures presented a more settled and positive sense of belonging and identity than he felt were available to him through his fragile relationship with his own family and 'community'. Indeed, his most positive representations of family were the imaginary or fictitious ones that appeared in the films, computer games and television programmes he discussed prominently among his most 'important things'.

The fragility of some participants' possibilities for display was also illustrated by the loss of important spaces over the course of the project. By the time of her second interview, Channel had lost access to the living room and the décor she loved after an argument with her aunt. She was convinced that she could no longer go back to her aunt/ grandfather's place and felt bereft as a result. She was pale and had self-harmed, and related that before leaving on the fateful night of the argument, she had ripped a piece of the wallpaper from the wall. This strip of prized wallpaper was now stored in a box at her boyfriend's place, out of sight.

This poignant story reinforces the importance to Channel both of her aunt/grandfather's living room and of the opportunity presented by the first interview to display this place and discuss its family connections. However, it also reflects the profound loss associated with losing access to this space and the consequent even greater fragility of her possibilities for displaying family, left as she was with a fragment of wallpaper she could not easily show to others. The photos she had presented happily and proudly in the first interview were now somewhat tainted in retrospect, now charged with a sense of loss. Although subsequent discussions revealed that Channel herself did not see it in this way, the researchers also worried that this sense of loss was reinforced by the second interview itself and potentially by the subsequent storage of the first interview photos in a research archive. Such reflections suggested the potential power, but also risks associated with the creation and storage of such emotionally-loaded visual artefacts in the absence of careful consideration and sufficient contextualisation for subsequent viewers.

For Gordon '[t]o be haunted is to be tied to historical and social effects' (2008, p. 190). In her view, hauntings are important in encouraging thoughts of the possibility of different futures. As part of this argument, she contends that hauntings may provide a further spur to consider how the social structural underpinnings of such experience might become more visible in a political context in which experiences are often not 'recognised as social but taken to be private, idiosyncratic, and even isolating' (2008, p. 132 citing Williams 1977, p. 128). It is cautiously argued that the sensory and imaginative methods used in this project produced data that can highlight such hauntings or the effects of social structural disadvantage, thus restoring some complexity to young lives that tend to be treated reductively and viewed in exclusively problematic terms. For example, both the photographs of Channel's aunt's living room and the wallpaper she later took from it point to important presences and absences over time and to how her own agency in trying to preserve such spaces was constrained not only by others, but also by her lack of material resources. When contextualised by surrounding discussion then, these photos lend not only to an appreciation of the 
warmth of many of her relationships, but also to an appreciation of their fragility, potentially prompting questions as to why this should be.

The context in which such data are presented is important however. The production of such visual artefacts allowed for the possibility of more innovative communication of results than often follows research reports. Attempts to mobilise such possibilities have included a multi-media installation used at the research launch, practice and policy conferences, and in practitioner training, and a website containing much audio and visual project data. These have been welcomed as 'hitting home' more forcefully than conventional presentations, or at least questioning perceptions of certain aspects of social work processes. ${ }^{4}$ It seemed that such short-lived exhibitions, including drawings, films composed of the photos and music produced by participants as at the research launch, opened up conversations for and between the numerous participants present, and carers, practitioners, policymakers and researchers. It may be therefore that such installations have the potential to shift 'policies, politics and public imaginations' (Falconer and Taylor, 2014), in significant, but hard-to-measure, ways.

However, changing perceptions, and more ambitiously, challenging underlying cultures focused on individual behaviour and motivations rather than social structural circumstances, may require much further thought. Notably, the 'haunting' produced by such discussions and artefacts may be double-edged for the participants. As Miller (2008) argues, 'emptiness' within home spaces or lack of material possessions can be associated with a lack of integration into places or relationships. These methods identified such absences in a way that was generally unintrusive and non-pathologising for the interviewees. Indeed, it was often reported to us that participants really enjoyed the project, and all wanted to complete the second interview, even if this proved impossible to organise in some remote areas. However, some discussions were emotional. One of the older interviewees was upset at the end of his first interview (although he was very happy to complete a second). While it is not argued that such upset can or should be completely avoided, one issue to be considered carefully is that the production of somehow more concrete, often visual artefacts for interviews may 'stay' with interviewees longer than some of their words, especially when stored in an archive. For example, such images, particularly if displayed alone, might in some way solidify or become reified into hard-to-diffuse or escape negative imagery of the interviewees' lives, reinforcing any sense they (and subsequent viewers) might have that things could never change in their lives, in contrast to the imagination of different futures envisaged by Gordon.

Participants' decisions not to comply with the 'running script' in taking or displaying images of places or things they were happy to talk about in their interviews may have reflected similar concerns. Notably, in interview discussion Reggie emphasised a lack of connection with the second hand items of furniture in his flat ('furniture without memories'?) but while he identified it as his 'least favourite place', did not take any photos of this poorly 
appointed and rather empty bedsit for the project. On reflection, Reggie's non-compliance when it came to providing pictures of the flat he so disliked may have related to a sense that the production of such images might only serve to somehow permanently associate him with it, or to deny his agency and the possibilities of change, however much he felt he had or could move on. Reggie also refused to respond when an agency with which he was involved asked him to provide an update of his circumstances in part to help the author with evidencing the measurable 'impact' of the project for an ESRC impact report. ${ }^{5}$ Such a reflection recalls another respondent's feeling of being defined by old reports contained in social work files and read out at children's hearings long after the event. At the same time, Reggie was willing to participate in person at the research launch and produce and discuss drawings to communicate his loneliness later for a very specific project output aimed at convincing policy makers and practitioners to improve particular services. All of these experiences suggest the importance of taking this 'flipside' of 'haunting' into account when considering the 'places' in which to show such artefacts. In particular, they suggest that the anonymised and relatively uncontextualised storage of items in archives may raise different, and potentially more problematic, issues than their more ephemeral but explicated presentation in an exhibition. Notably, although this study cannot present any evidence to this effect, archiving may unintentionally confer a sense of permanence to the circumstances presented in terms both of individual trajectories and in relation to the broader representation and imagination of particular social groups.

\section{Conclusion}

This chapter has focused on intimacies and consumption in a broad sense and among less privileged young people not living in conventional 'family' circumstances. It builds on critical approaches to consumption in its focus on the less affluent, and its exploration of the importance of items with little or no monetary value. Consumption here also includes the use of objects and places belonging to others, a more collective notion of consumption perhaps than often employed. This chapter has highlighted the worth of such consumption to young people in negotiating more difficult emotional and sometimes material circumstances. It illustrates for example how access to certain décors and the presence, feel and smell of such keepsakes, such as teddies, can provide a sense of 'haptic' belonging across many years, retaining a sense of presence, however imaginary, in the face of important absences. It also identifies how the 'display' of such items, including through the medium of the interview process, may further contribute to a sense of belonging by indicating the young person's inclusion within some sort of viable family history, future or place. In addition, this chapter points to the research process itself as providing a further opportunity for the display of important relationships and of comfortable or more ambivalent sense of non-belonging through photos and drawings of important things and places. The importance of this opportunity was accentuated in particularly constrained and 
difficult circumstances such as secure care from which participants could not access much loved people, places and things to take photographs of them, but could draw them.

The chapter also raises issues connected to the production and 'consumption' of images by researchers, practitioners, policymakers and ultimately, the general public, pointing to how these artefacts may feed into public imaginations of particular issues and groups within society. Notably, it suggests that the visual artefacts produced in such research may 'haunt' the viewer in a different way to conventional research reports. It is argued that it is important for researchers, research councils, and other funders to consider the potential effects of their work on participants in somehow 'freezing' the social and individual imaginary of their potential trajectories. It is possible, for example, that the production of such photos, or their long-term storage in archives, that do not sufficiently contextualise this material, or link easily between the diverse types of data deposited for a participant, might lead to the coagulation of a sense of helpless vulnerability. This possibility that recalls similar critiques of famine photography, of representations of AIDS orphans (Meintjes and Geise, 2006) or 'damaged' children (O’Dell, 2008). In other words, archiving processes may have a reductive effect, removing complexity from the representation of participants' circumstances and denying them the possibility of a more open-ended future. As such, the current focus on the anonymisation of images and transcripts may need to be revised at least in part, to allow for the provision of greater context in relation to individual artefacts, and better linkages between different types of data from a project provided. These concerns have weighed heavily on the author and have made their consideration of research council requirements to archive all material from projects, and the claim of such organisations to be best placed to make decisions as to the sensitivity of data particularly difficult to negotiate. Such concerns also raise questions as to the ways research councils' need to 'evidence' impact in conventionally measurable ways may focus attention away from other options. The experience of this project pointed particularly to the possibilities opened up by more ephemeral exhibitions highlighting the haunting effects of 'seething absences' and structural conditions underlying the participants' complex lives in the way Gordon (2008) argues. It is hoped that further similar discussions and thought will develop ethically sensitive and effective ways of doing so.

\section{Acknowledgements}

The author would like to thank Dr. EJ Milne, the Research Fellow on the project on which this chapter draws, as well as all of the project participants and the workers who helped us with recruitment. The project Young People Creating Belonging: Spaces, Sounds and Sights was funded by the Economic and Social Research Council (UK) (RES-061-250501).

\section{References}


Allett, N. (2010) Sounding Out: Using Music Elicitation in Qualitative Research (Realities Working Paper 14). Manchester: National Centre for Research Methods.

Baynes, P. (2008) 'Untold Stories: A Discussion of Life Story Work', Adoption and Fostering, 32(2), 43-49.

Brodzinsky, D., Smith, D. and Brodzinsky, A. (1998) Children's Adjustment to Adoption: Developmental and Clinical Issues. Thousand Oaks: Sage.

DeNora, T. (2000) Music in Everyday Life. Cambridge: Cambridge University Press.

Falconer, E. and Taylor, Y. (2014) 'Making Space for Religion, Youth and Sexuality? Implications for Policies, Politics and Public Imaginations', www://weekscentreforsocialandpolicyresearch.wordpress.com/2014/09/02/making-space-forreligion-youth-and-sexuality-implications-for-policies-politics-and-public-imaginations/

Finch, J. (2007) ‘Displaying Families’, Sociology , 41(1), 65-81.

Gordon, A. (2008) Ghostly Matters: Haunting and the Sociological Imagination. London: University of Minneapolis Press.

Illouz, E. (2007) Cold Intimacies: The Making of Emotional Capitalism. Cambridge: Polity Press.

Livingstone, S. and Haddon, L. (2008) 'Risky Experiences for Children Online: Charting European Research on Children and the Internet', Children and Society, 24, 75-83.

Livingstone, S., Haddon, L. and Görzig, A. (2012) Children Risk and Safety on the Internet: Research and Policy Challenges in Comparative Perspective. Bristol: Policy Press.

Mason, J. and Davies, K. (2010) 'Coming to Our Senses? A Critical Approach to Sensory Methodology', Qualitative Research, 95, 587-603.

Meintjes, H. and Giese , S. (2006) 'Spinning the Epidemic: The Making of Mythologies of Orphanhood in the Context of AIDS', Childhood, 13(3), 407-30.

Miller , D. (2008) The Comfort of Things. Cambridge: Polity.

Miller, D. (2010) Stuff. Cambridge: Polity.

Milne, E.J., Mitchelland, C. and De Lange, N. (2012) The Handbook of Participatory Video. Lanham, MD: AltaMira Press.

Morgan, D. (1996) Family Connections: An Introduction to Family Studies. Bristol: Policy Press.

Morrow, V. (2001) 'Using Qualitative Methods to Elicit Young People's Perspectives on Their Environments: Some Ideas for Community Health Initiatives', Health Education Research $16,3,255-68$. 
O’Dell, L. (2008) 'Representations of the 'Damaged' Child: 'Child Saving' in a British Children's Charity Ad Campaign', Children and Society, 22, 383-392.

Osvaldsson, K. (2011) 'Bullying in Context: Stories of Bullying on an Internet Discussion Board', Children and Society, 25(4), 317-327.

Pink, S. (2009) Doing Sensory Ethnography. London: Sage.

Rasmussen, K. (2004) 'Places for Children - Children's Places', Childhood, 11(2), 155-174.

Rose, G. (2007) Visual Methodologies, 2nd edn. London: Sage.

Williams, R. (1977) Marxism and Literature. Oxford: Oxford University Press.

Wilson, S. (2014) 'Using Secondary Analysis to Maintain a Critically Reflexive Approach to Qualitative Research', Sociological Research Online, 19(3), 21. http://www.socresonline.org.uk/19/3/21.html

Wilson, S. (forthcoming 2015) 'Digital Technologies, Relationships and Self-care: Children and Young People Looking after Themselves in Difficult Circumstances', Children's Geographies

Wilson, S., Cunningham-Burley, S., Bancroft, A. and Backett-Milburn, K. (2012a) 'The Consequences of Love: Young People and Family Practices in Difficult Circumstances', Sociological Review, 60(1), 110-128.

Wilson, S., Houmøllerand, K., Bernays, S. (2012b) 'It Just Feels Nice to Go Home to a Nice Home, and Not, Some House': Taking Account of the Sensory Construction of Difficult Family Relationships in Domestic Spaces', Children's Geographies, 12(1), 101-113.

1 To explore data from the project including participant-produced photos, sound recordings, drawings, music and a film, please go to: http://www.researchunbound.org.uk/young-peoplecreating-belonging/

2 The advisory group also included representatives of national children's organisations including the SCRA and Children 1st as well as social work and sociology academics with expertise in visual methodologies and theories of personal relationships.

${ }^{3}$ Pseudonyms, as chosen and spelt by the respondents, are used throughout this chapter.

4 For a generous account of the research launch/ exhibition installation please see: http://blogs.iriss.org.uk/apmusings

${ }^{5}$ The ESRC has recently introduced a requirement that funded researchers file an impact report 12 months after the end of the funded period of a project. Researchers must evidence ways in which their project has had 'impact' beyond academia, for example through influencing policy and 
practice in measurable ways and are generally required to archive their data - including photosfor the use of future researchers and others. These reports are then used by the research councils to justify their own activity to government. 